\title{
One-dimensional dynamic gas-solid flow model for a full-loop CFB
}

\author{
Lu Shan ${ }^{1}$, Boyu Deng ${ }^{1}$, Yuxin $\mathrm{Wu}^{1}$, Xinyu Gao ${ }^{2}$, Man Zhang ${ }^{1}$, Hairui Yang ${ }^{1}$, and \\ Mingming $\mathrm{Gao}^{3}$ \\ ${ }^{1}$ Tsinghua University \\ ${ }^{2}$ Harbin Boiler Co Ltd \\ ${ }^{3}$ North China Electric Power University
}

May 5, 2020

\begin{abstract}
Circulating fluidized bed (CFB) boiler is applied for peak-load regulation nowadays, with the rapid increase of renewable energy generation in the power grid. However, due to the huge inertia in CFB system, it is important to investigate the operational characteristics of CFB boiler to achieve depth peak load cycling. In this study, a one-dimensional dynamic model for gas-solid hydrodynamics in a full-loop CFB boiler is established. The model was validated by the field test data of a $350 \mathrm{MW}$ supercritical CFB boiler. The impact of the changing speed for extra operating conditions, the total bed inventory, and the size distribution of the feeding ash particles under the load reduction process were analyzed. The results show that there is an optimal load changing rate under load reduction process. The total bed inventory being higher and feeding relatively larger particles benefit to achieve a better performance in a load reduction process.
\end{abstract}

\section{Hosted file}

One-dimensional dynamic gas-solid flow model for a full-loop CFB.docx available
https://authorea.com/users/292822/articles/420623-one-dimensional-dynamic-gas-solidflow-model-for-a-full-loop-cfb 

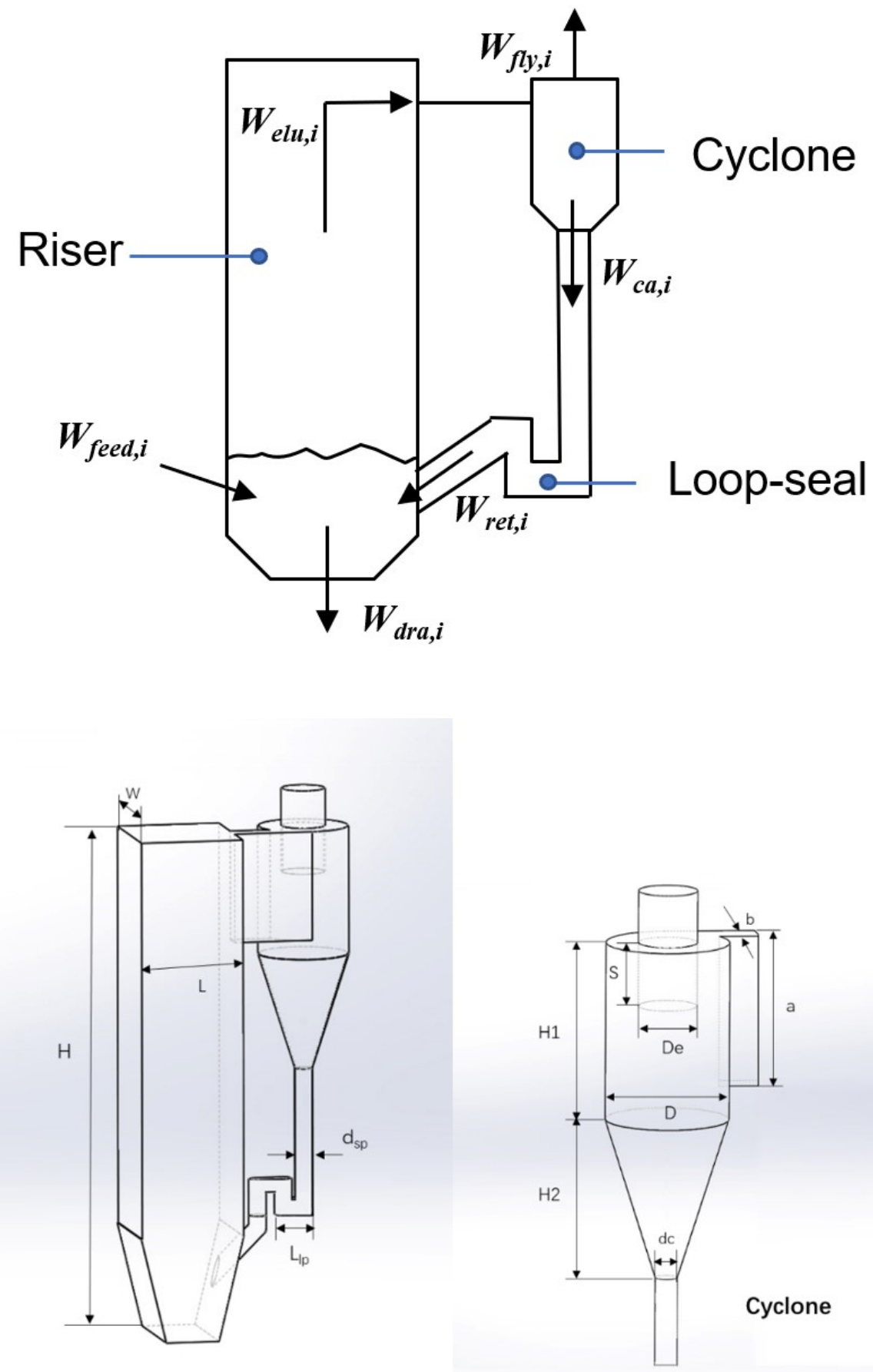


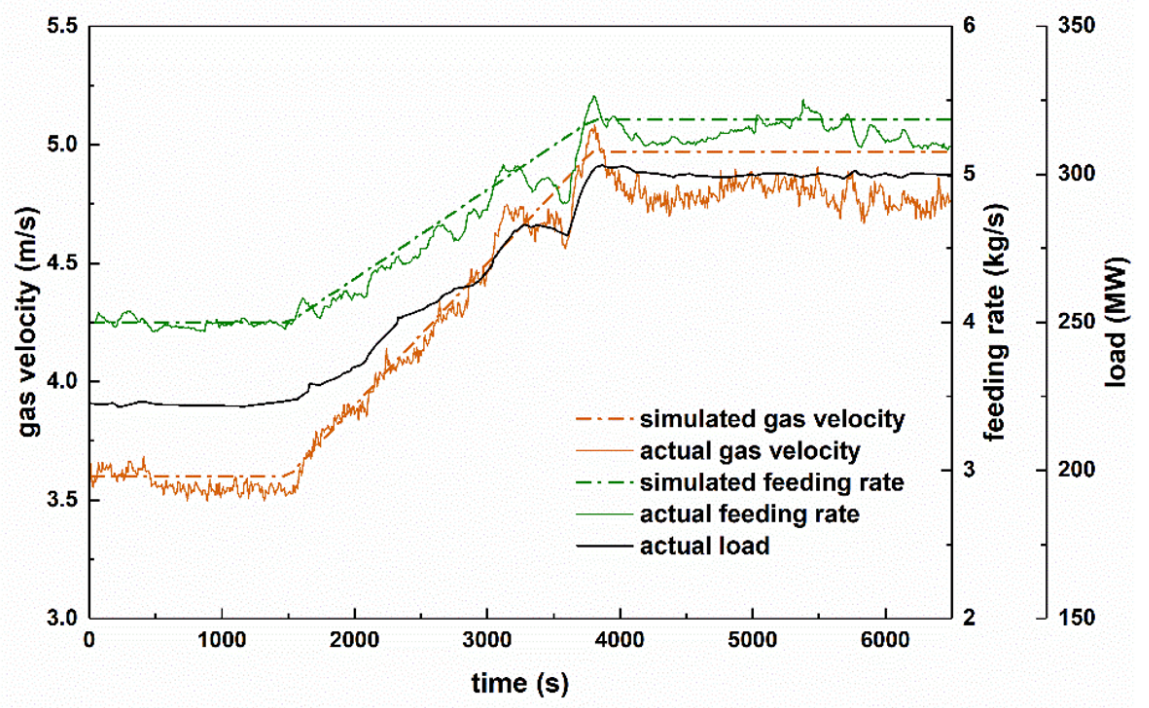

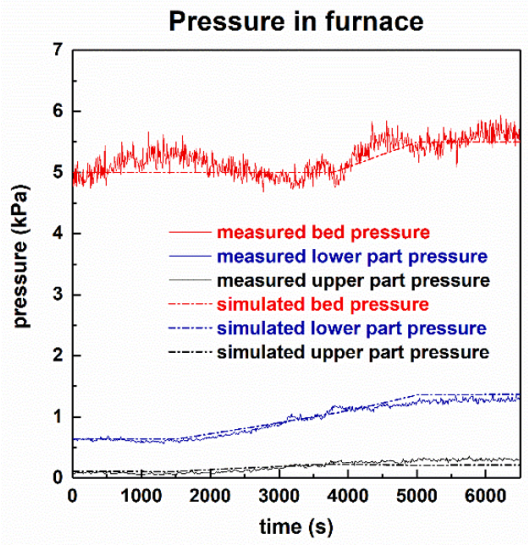

(a)



(b) 



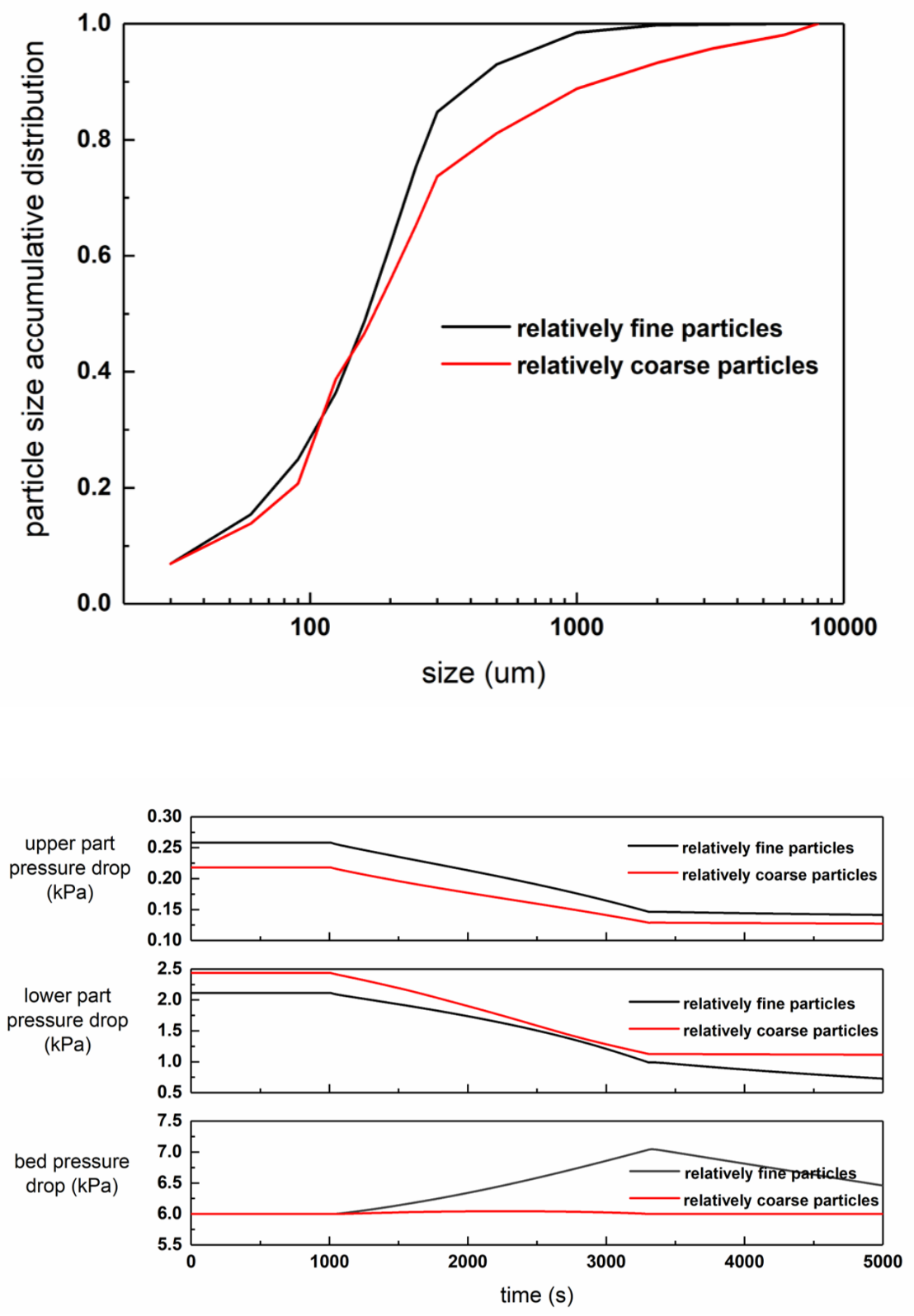